\title{
Article \\ Case Studies and Challenges of Implementing Geotechnical Building Information Modelling in Malaysia
}

\author{
Min Lee Lee ${ }^{1}$, Yee Linn Lee ${ }^{2}$, Sxue Liang Goh ${ }^{1}$, Chai Hoon Koo ${ }^{2, *}$, See Hung Lau ${ }^{2} \mathbb{D}$ and Siaw Yah Chong ${ }^{2}$ \\ 1 Faculty of Science and Engineering, University of Nottingham Malaysia, Jalan Broga, \\ Semenyih 43500, Malaysia; minlee.lee@nottingham.edu.my (M.L.L.); keey6gsl@nottingham.edu.my (S.L.G.) \\ 2 Lee Kong Chian Faculty of Engineering and Science, Universiti Tunku Abdul Rahman, Jalan Sg. Long, \\ Bandar Sg. Long, Cheras, Kajang 43000, Malaysia; yeelinn10@1utar.my (Y.L.L.); laush@utar.edu.my (S.H.L.); \\ chongsiawy@utar.edu.my (S.Y.C.) \\ * Correspondence: kooch@utar.edu.my
}

check for updates

Citation: Lee, M.L.; Lee, Y.L.; Goh, S.L.; Koo, C.H.; Lau, S.H.; Chong, S.Y. Case Studies and Challenges of Implementing Geotechnical Building Information Modelling in Malaysia. Infrastructures 2021, 6, 145. https://doi.org/ $10.3390 /$ infrastructures6100145

Academic Editors: Andreas Benardos, Dimitrios Kaliampakos and Pavlos Nomikos

Received: 2 September 2021

Accepted: 22 September 2021

Published: 12 October 2021

Publisher's Note: MDPI stays neutral with regard to jurisdictional claims in published maps and institutional affiliations.

Copyright: (c) 2021 by the authors. Licensee MDPI, Basel, Switzerland. This article is an open access article distributed under the terms and conditions of the Creative Commons Attribution (CC BY) license (https:/ / creativecommons.org/licenses/by/ $4.0 /)$.

\begin{abstract}
Unforeseen ground conditions are some of the main contributors to construction cost overruns and late completion. Recent research trends have witnessed the scopes of building information modeling (BIM) technology being extended to subsoil and substructure constructions, or simply known as geotechnical BIM. This paper aimed to explore the procedures of developing 3D subsoil models through two case studies in Malaysia. The geotechnical BIM processes were performed by commercial software, AutoCAD Civil 3D 2017, with the extension of the Geotechnical Module. The modeling procedures can be divided into three main stages, namely data collection, data interpretation, and data visualization. The subsoil models were successfully developed at different levels of detailing to serve for different applications. The results showed that the 3D subsoil modeling required huge modeling and computational efforts, particularly when dealing with tropical residual soil profiles in Malaysia that are highly intricate. Thus, an adequate soil strata generalization was required to simplify the generated subsoil model. Data collection and management was identified as one of the main challenges of promoting geotechnical BIM in Malaysia at a macro-scale. Despite the challenges, successful implementation of the geotechnical building information in the present case studies were proved to be capable of promoting interoperability of soil data, which is an essential element in sustainable construction.
\end{abstract}

Keywords: geotechnical building information modelling; 3D subsoil model; soil investigation; residual soi; soil strata

\section{Introduction}

Cost over-runs and late completion are the two most common problems encountered in construction project management. The problems can be caused by numerous factors such as design error, unforeseen site conditions, shortage of resources, climate change, improper planning, etc. Mohammed et al. [1] reported that unforeseen subsoil conditions are some of the main factors contributing to the construction over-runs. This is supported by the fact that interpreting properties of natural subsurface materials is always a more complicated task than analyzing man-made superstructures. Morin [2] suggested that site investigation is essential to analyze anomalies in ground, which can significantly increase the cost of a project if the subsurface condition is left unidentified.

Variability and heterogeneity of soil properties constitute one of the main uncertainties to construction planning and risk management. The situation is worsened by typically thick tropical residual soils in Malaysia. Residual soils cover more than two thirds of the land area in peninsular Malaysia [3]. The characteristics and properties of these residual soils are known to be highly variable. This is because residual soils are products of chemical weathering in which their properties depend upon several factors such as climatic factors, parent materials, topography, drainage condition, and age [4]. Engineers normally rely on 
individual experience and judgment to predict the overall subsoil conditions of based on limited information retrieved from soil investigations.

Building information modelling (BIM) was first introduced in the late 1970s as an intelligent modelling process to store information into a shared and collaborative model file, which can be accessed by multidiscipline parties within a project team. The application of BIM has effectively improved coordination, planning, and management of construction projects while reducing risks of cost and schedule over-runs [5]. In recent years, there has been rapid advancement in the research pertaining to integration of BIM technology in geotechnical applications. Geotechnical BIM is a process of storing and integrating geotechnical data into a BIM tool and generating a 3D model for subsurface information. Geotechnical BIM is implemented on substructure construction to model and visualize subsurface conditions with aims of reducing uncertainties associated with the underground constructions. It enables compilation, sharing, and visualization of 3D subsurface models which can be made accessible to all parties within a project team.

At present, the geotechnical BIM has been applied mainly to tunneling projects in developed countries such as the UK [6], Australia [7], Sweden [8], etc. Underground materials or features like geological faults, contamination, and earthwork mass can be determined and extracted from the 3D model. Morin et al. [9] demonstrated real-life benefits of performing geotechnical BIM through case studies in the UK. Successful implementation of the technology could result in a better cost control through the elimination of unforeseen problems and a better understanding of a project through data collaboration. Tawelian and Mickovski [10] conducted a questionnaire survey and case study to investigate opinions on integration of geotechnical data into BIM among Scottish geotechnical community. They highlighted that multiplicity of formats as one of the main stumbling blocks for promoting geotechnical BIM process.

Studies and implementations of geotechnical BIM in developing countries like Malaysia are still very limited. Malaysia is located within the tropical region where residual soils can be found abundantly. In addition to the extreme climate, inconsistent geology and subsurface conditions have all contributed to more challenges to geotechnical BIM processes in local practice. The geological formations vary considerably depending on geographical locations (Figure 1). The complex soil profile and geological formations in Malaysia could have resulted in a more complex workflow for the implementation of geotechnical BIM. This study aimed to explore procedures and challenges of developing 3D subsoil models through two case studies in Malaysia. 


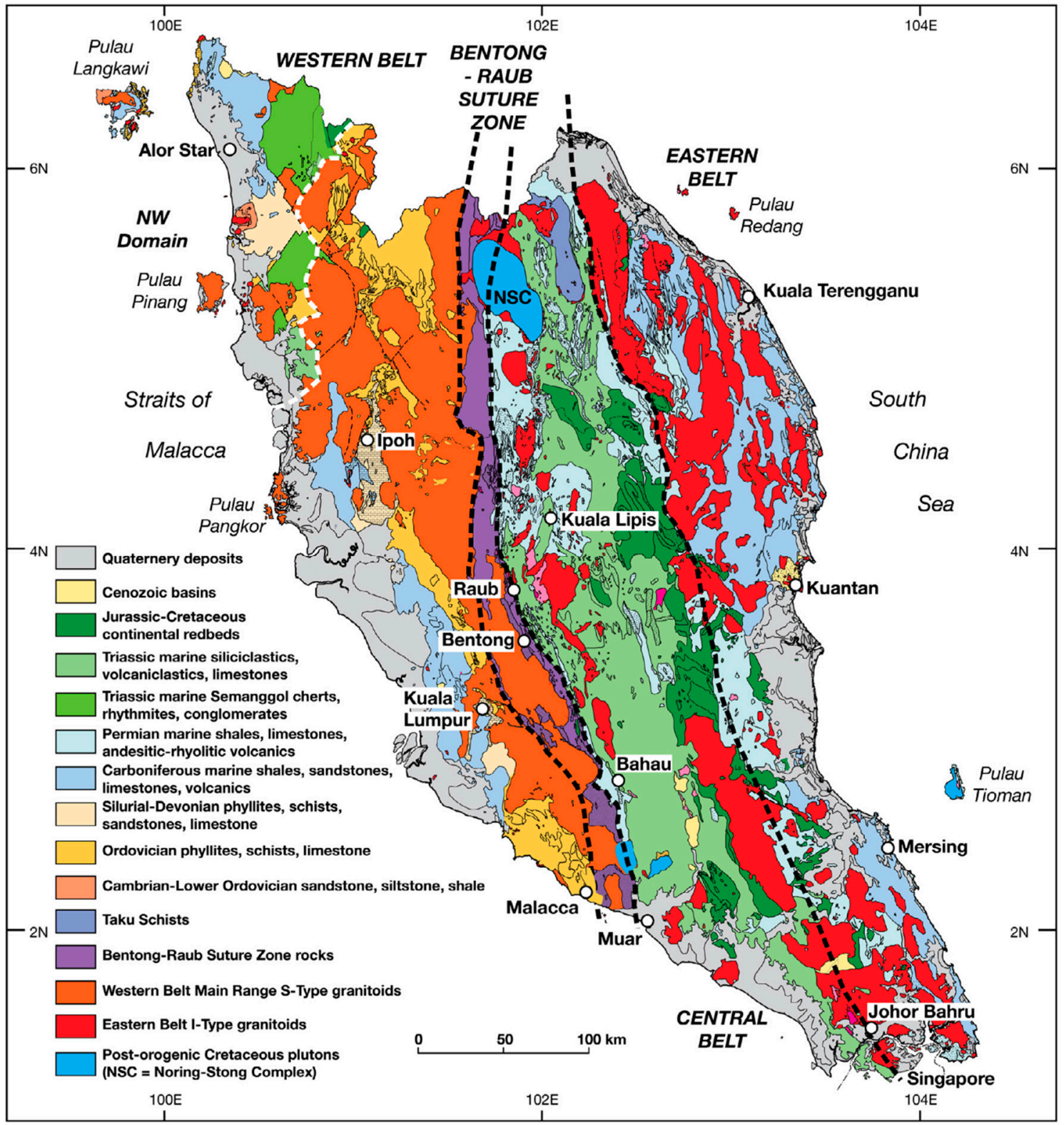

Figure 1. Simplified geological formations of Peninsular Malaysia (Modified from [11]).

\section{Site Descriptions}

\subsection{Case Study 1}

Case study 1 was located at the north of Petaling Jaya District, Selangor, Malaysia (coordinates $3^{\circ} 7^{\prime} 30^{\prime \prime} \mathrm{N}, 101^{\circ} 34^{\prime} 5^{\prime \prime} \mathrm{E}$ ). The site is underlain by the typical granitic rock formation in Klang Valley area. It is well documented that a thick residual soil layer (>15 m) is normally formed above this type of granitic bedrock [12]. Figure 2 shows the layout plan of the proposed site encompassing a total area of $2573.6 \mathrm{~m}^{2}$ with 75 numbers of boreholes completed for soil investigation. 


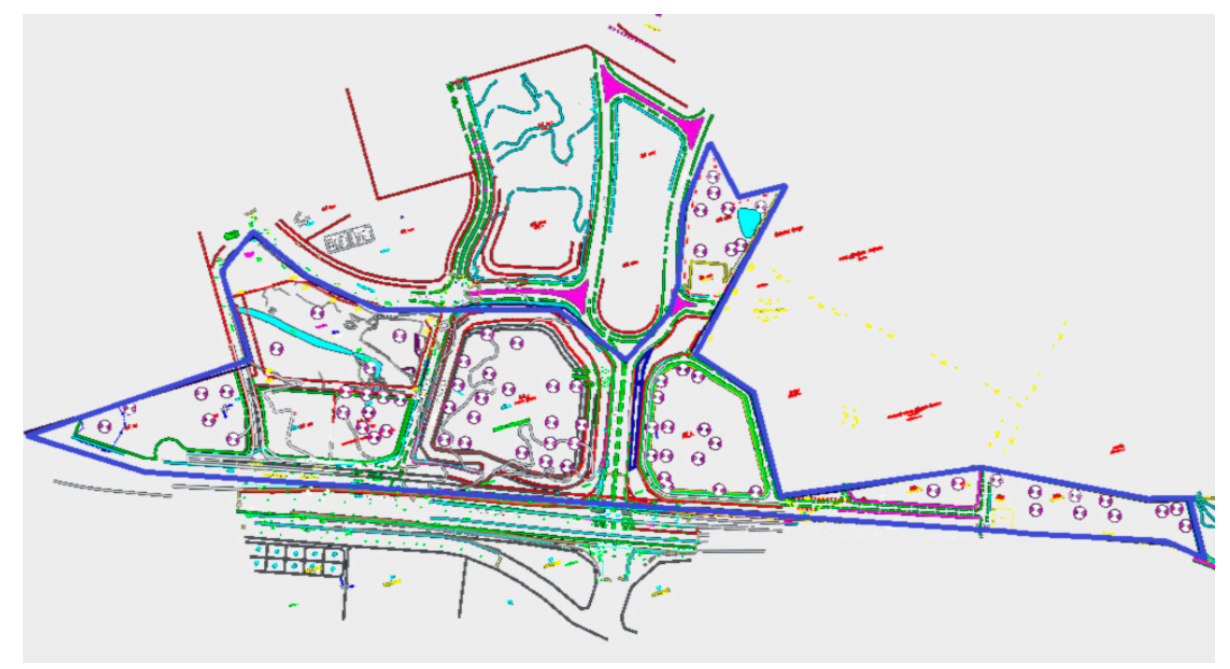

Figure 2. Layout plan of Case Study 1.

\subsection{Case Study 2}

Case study 2 was located at the southeast of Kuala Selangor District, Selangor, Malaysia (coordinates $3^{\circ} 15^{\prime} 15^{\prime \prime} \mathrm{N}, 101^{\circ} 27^{\prime} 00^{\prime \prime} \mathrm{E}$ ). The site is underlain by the Kenny Hill formation, a metamorphic rock formation comprising of schists, phyllites, and others that were formed from the metamorphism of shale, sandstones, and other similar sedimentary rocks [13]. Numerous geohazards have been associated with this geological formation such as slope failure, collapse deposits at the interface with the underlying Kuala Lumpur Limestone, variable residual soil strength caused by contrasting interbedded lithologies, and lateritic concretions and hardpans [14]. Figure 3 shows the layout plan of the proposed site with the locations of 18 boreholes.

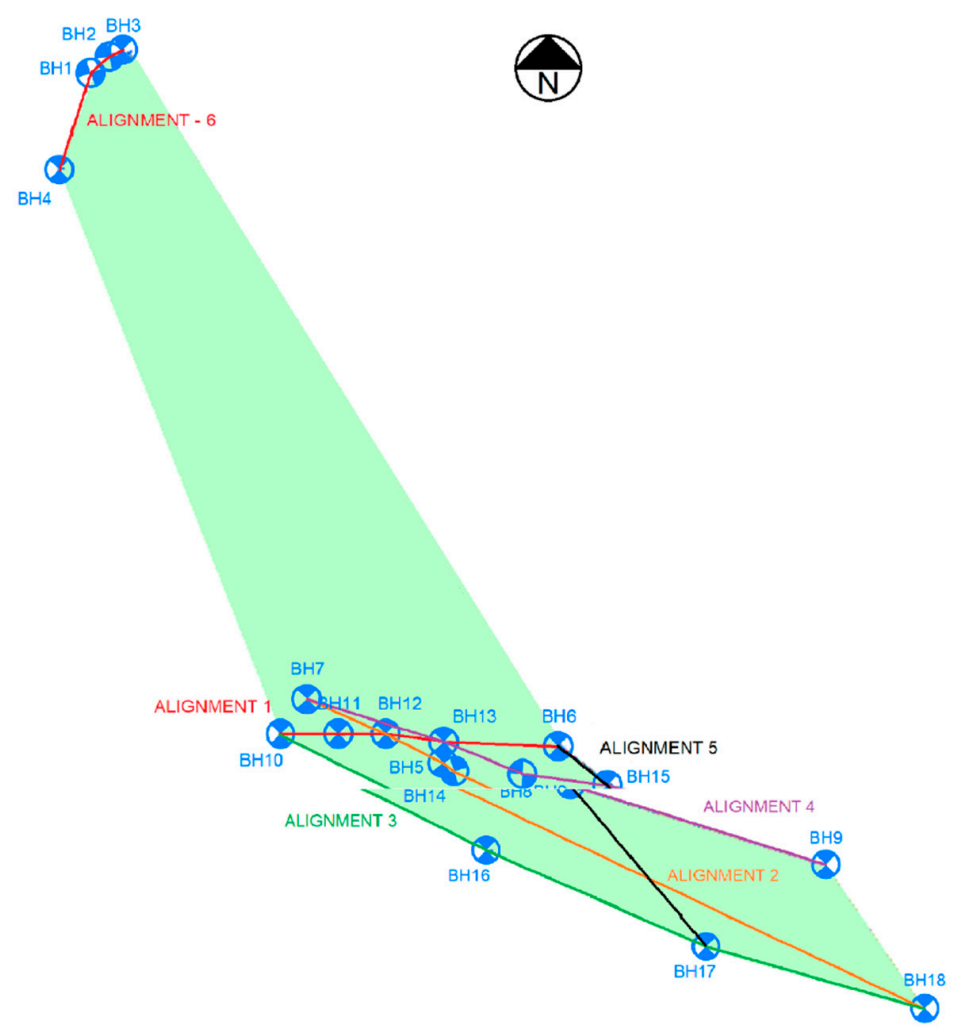

Figure 3. Layout plan of Case Study 2. 


\section{Data Collection}

The soil investigation and topography data of the studied sites were collected from developers in charge of the projects. Subsoil information including soil physical properties, Standard Penetration Test (SPT) ${ }^{\prime} \mathrm{N}$ values, soil engineering properties test results, water tables, and etc. were extracted from soil investigation reports. Topography data were obtained from land surveys conducted at the sites. For Case Study 1, the site was located on relatively flat ground with the highest and lowest reduced levels (RL) falling in the range of $11 \mathrm{~m}$ and $21 \mathrm{~m}$, respectively, while Case Study 2 was located on a hilly area with the RL ranging from $11 \mathrm{~m}$ to $51 \mathrm{~m}$.

\section{Data Interpretation}

The soil investigation and topography data were processed and interpreted before they were used for the subsequent 3D modelling. These processes are explained in detail in the following sub-sections:

\subsection{Digitization of Soil Investigation (SI) Data to the American Geotechnical and Geoenvironmental Specialist (AGS) Format}

It is common practice in Malaysia that the soil investigation reports are submitted to the parties of interest in the form of hardcopy or softcopy in PDF format. Therefore, the data were required to be extracted and digitized into a standard format to enable information sharing on the same platform among all stakeholders. In 1991, the American Geotechnical and Geoenvironmental Specialists (AGS) developed a method for transferring the geological data between different software within geological industry, which is widely known as "AGS format". The AGS format has since received continuous updating and the latest released version to date is version 4.0.4. This is an important element in realizing Geotechnical BIM to enable all geological and geotechnical industry players work on a universal format of data entry. Most of the geotechnical BIM software in the current market allow importing the input data in the AGS format. A list of unique legend codes for 159 types of soil materials were suggested in the AGS format. These legend codes were assigned manually to each type of soil based on their geological descriptions.

\subsection{Conversion of the AGS Format to CSV Format}

Another alternative way of inputting the soil information data into a geotechnical BIM tool is using CSV format. The CSV format requires less information compared with the AGS format. Two CSV files were created, namely the "Field Geological Descriptions" file and the "Location Details" file. The "Field Geological Descriptions" file was used for inputting the borehole identity, the depth of each soil layer, and the legend code and its corresponding geological descriptions, while the "Location details" contained coordinates, borehole termination depth, and reduced level.

\subsection{Soil Generalization}

To simplify the modelling efforts, an attempt was made to generalize the soil profiles based on their dominant compositions and SPT'N values. The soils were categorized into six categories based on their compositions, namely gravel, sand, silt, clay, hard layer, and rock. In terms of soil stiffness, the cohesive soils were divided into four categories, i.e., soft $\left(\mathrm{SPT}^{\prime} \mathrm{N}=0-4\right)$, firm-stiff (SPT $\left.\mathrm{N}=4-15\right)$, very stiff $\left(\mathrm{SPT}^{\prime} \mathrm{N}=15-30\right)$, and hard $\left(\mathrm{SPT}^{\prime} \mathrm{N}=30-50\right)$. For cohesionless soils, the stiffness categories were named as soft ( $\left.\mathrm{SPT}^{\prime} \mathrm{N}=0-4\right)$, loose ( $\left.\mathrm{SPT}^{\prime} \mathrm{N}=4-10\right)$, medium dense (SPT' $\left.\mathrm{N}=10-30\right)$, and dense $\left(\mathrm{SPT}^{\prime} \mathrm{N}=30-50\right)$. Hard layer was defined as materials with $\mathrm{SPT}^{\prime} \mathrm{N}>50$. As soil interpretation and generalization relied heavily on professional judgement and experience, consultations with a practicing engineer and geologist were necessary to ensure correctness of the data interpretation. 


\subsection{Digitization of Topography Data}

The coordinates and reduced levels of boreholes are essential information for generating the topography layer of the 3D subsurface model. The information was extracted from the SI reports. For some boreholes with missing topography data, their coordinates and reduced levels were interpolated from the $2 \mathrm{D}$ topography map. The data were input into the AGS and CSV formats as described above.

\section{Data Visualization}

AutoCAD Civil 3D 2017 (Autodesk Inc., San Rafael, CA, USA) with the extension of Geotechnical Module was used as the geotechnical BIM tool in the present study. The modeling was performed by importing the above-mentioned CSV files into the software. Dummy boreholes with the soil profiles identical to their nearest boreholes were created to form the boundary of the project site. Upon completion of the modeling, random sections were cut through the 3D model to visualize the cross-sectional profile. The profile was then compared with the soil profile and interpreted manually by qualified personnel for verification. Any discrepancy was probed further to ensure correctness of the modeling.

\section{Results}

\subsection{Case Study 1}

The first attempt of modelling was performed by generating a 3D subsurface model based on the detailed SI data as extracted from the SI report (Figure 4). As the modeling involved data from a large number (75) of boreholes, the soil strata generated were found to be highly complicated. A total of 23 types of soil materials were modeled to represent different compositions of the in-situ soils which were indicated by the unique legend codes in accordance with the AGS format. It was difficult to extract useful information for practical design purposes based on the 3D soil profile as shown in Figure 4.

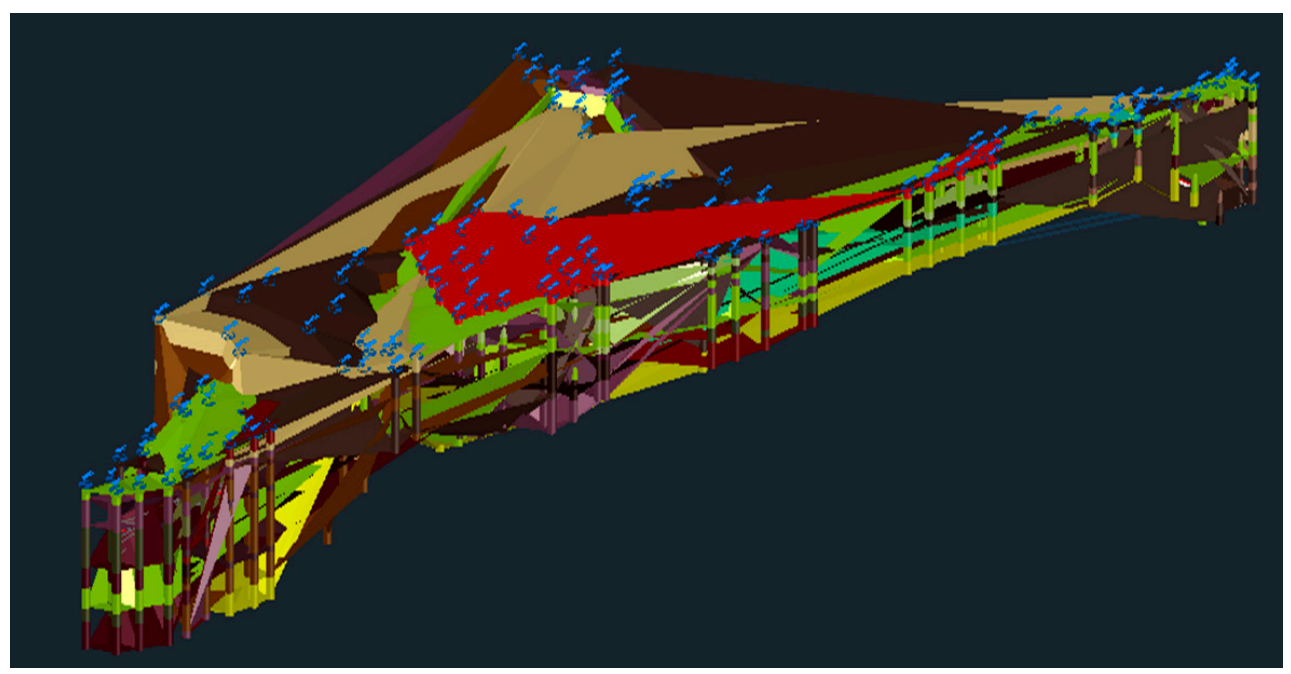

Figure 4. 3D subsurface model for Case Study 1 based on detailed soil investigation data.

Figure 5 shows the 2D borehole strip diagram and cross-sectional profile generated from a selected cut section. From Figures 4 and 5, the soil profile was highly intricate and diverse. Numerous pockets of diverse soil materials were bedded into the dominant soil layers. Granite rock was encountered at the termination levels of certain boreholes. These observations were consistent with the expectation of a typical residual soil profile on a granitic formation in Malaysia. Because of the complicated soil strata, huge modelling efforts were required to calibrate the model in order to make the produced soil strata presentable. Despite the calibration works, numerous overlaps of soil layers were still clearly visible in the soil profile as shown in Figure 5. 


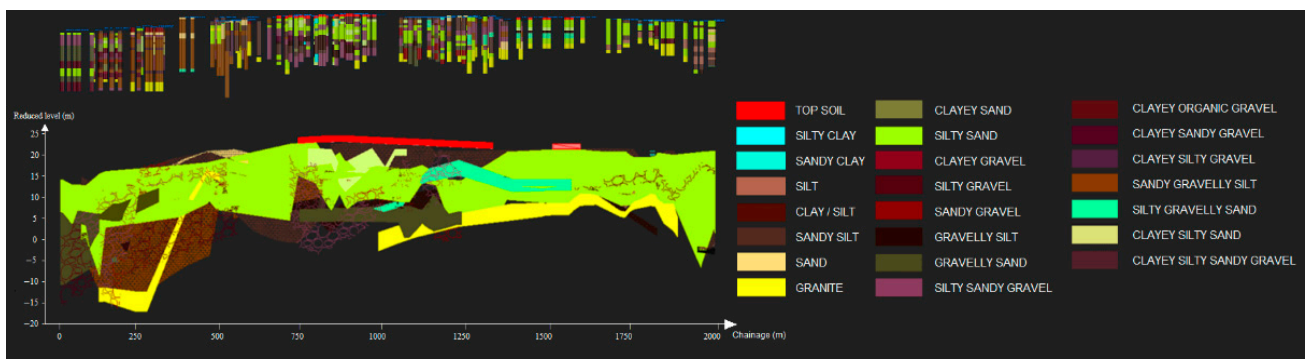

Figure 5. Cross-sectional profile for Case Study 1 based on detailed soil investigation data.

The second attempt aimed to generate a cleaner and more presentable 3D subsoil model (refer to Figure 6) by generalizing the soil strata into 7 main types only, i.e., top soil, gravel, sand, silt, clay, hard layer, and bedrock (granite). Apparently, this attempt successfully minimized the number of soil pockets bedded between dominant materials with the soil layering clearly visualized. Based on this modeling approach, it was easy to tell that the site mainly contained sandy materials with the hard layer varied from about Reduced Level (RL) $-11 \mathrm{~m}$ to $-5 \mathrm{~m}$. Some voids were bedded between soil strata, indicating layers with missing data from borelog or no recovery during soil investigation works.

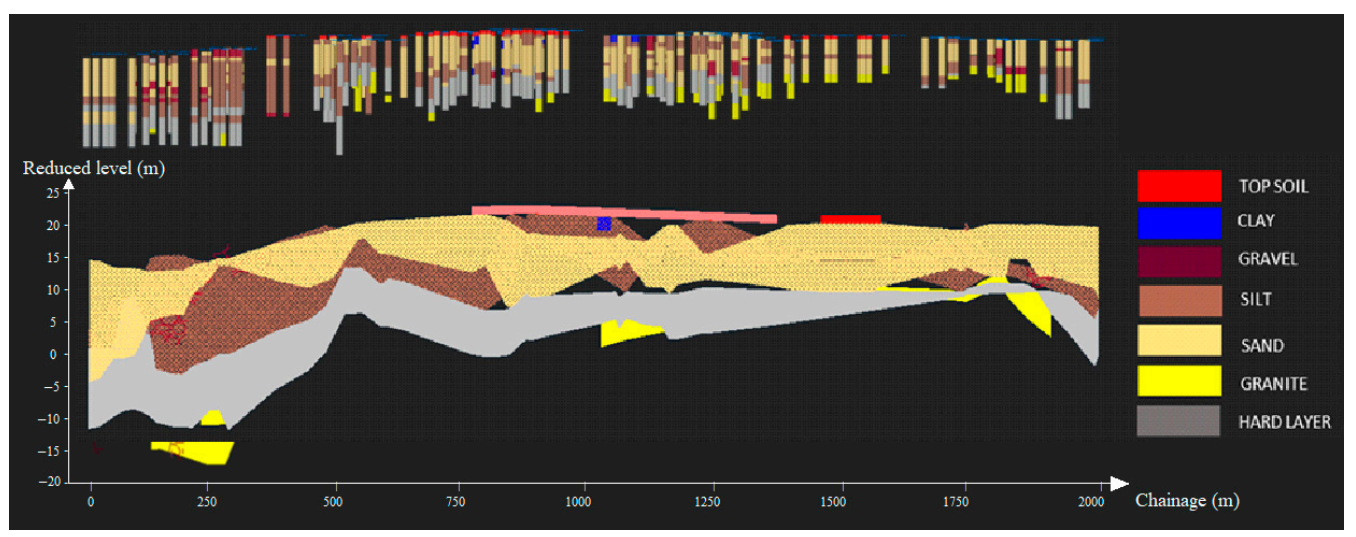

Figure 6. Cross-sectional profile for Case Study 1 based on generalized soil profile.

\subsection{Case Study 2}

Figure 7 shows the 3D subsoil model generated for the Case Study 2, while Figures 8 and 9 present the cross-sectional profiles cut along a selected section (Alignment 1) based on the generalized soil model and soil-hard layer/bedrock model, respectively. The results indicated that the 3D subsoil models were useful for visualizing the soil layering and level of hard layer/bedrock for a site that was characterized by large variations in topographic level. The latter model was useful for determining the depth of hard layer/bedrock, particularly for foundation design purposes. As compared with Case Study 1, the Case Study 2 comprised significantly less soil investigation data, as only 18 boreholes were completed at site. As the result, the soil profile generated was less complicated with lesser issues of overlapping layers. However, the challenge associated with Case Study 2 was that the soil properties and layering were very variable. For instance, soil profiles of Boreholes 10 and 13 (Figure 8) generally consisted of top soil and silt only, while the soil profile of Borehole 6 contained multiple layers of top soil, peat, silt, clay, sand, and gravel. Some calibration and manual interpretation works were required to ensure the continuity of the soil layering between Boreholes 13 and 6. Considering peat, clay, and gravel only existed in Borehole 6, but not in the adjacent Borehole 13, these soil layers that initiated from Borehole 6 were assumed to diminish gradually as they move to the adjacent borehole and terminate at Borehole 13. It was worth noting that the soil model developed based on this approach may not represent the actual field soil strata. It was merely a generalization of the soil strata 
in which the same soil types in adjacent boreholes were linked up to form the soil layers. In the event that the in-situ peat and clay soils in Borehole 6 were just pockets bedded into the dominant soil layers (silt and sand), the geological model as presented in Figure 8 would not be able to represent the actual geological conditions. From Figure 9, it was observed that the hard layer and the topographic surface of the site were highly variable. There was a sharp elevation change (about $40 \mathrm{~m}$ difference) in the hard layer between Boreholes 11 and 12. Through the present 3D subsoil modelling, it made the interpretation of the soil profile simpler and effectively minimized the possibility of misjudging important soil features such as those that may adversely impact geotechnical designs.

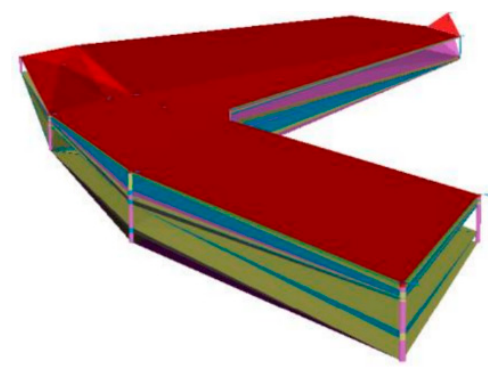

Figure 7. 3D subsurface model for Case Study 2 based on the detailed soil investigation data.

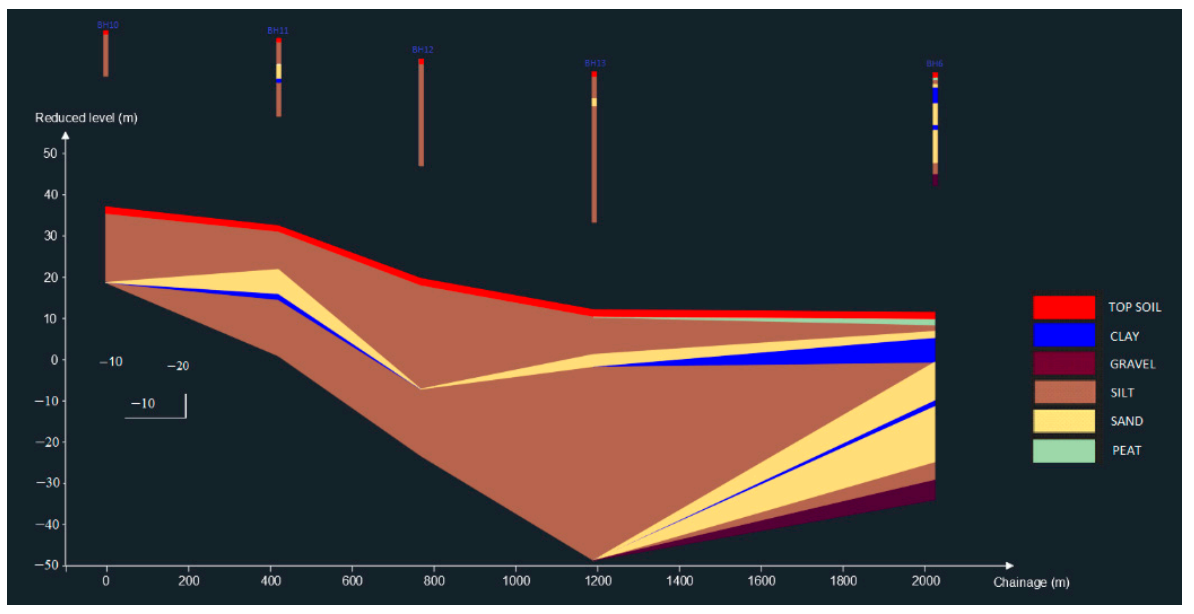

Figure 8. Cross-sectional profile for Case Study 2 based on generalized soil profile.

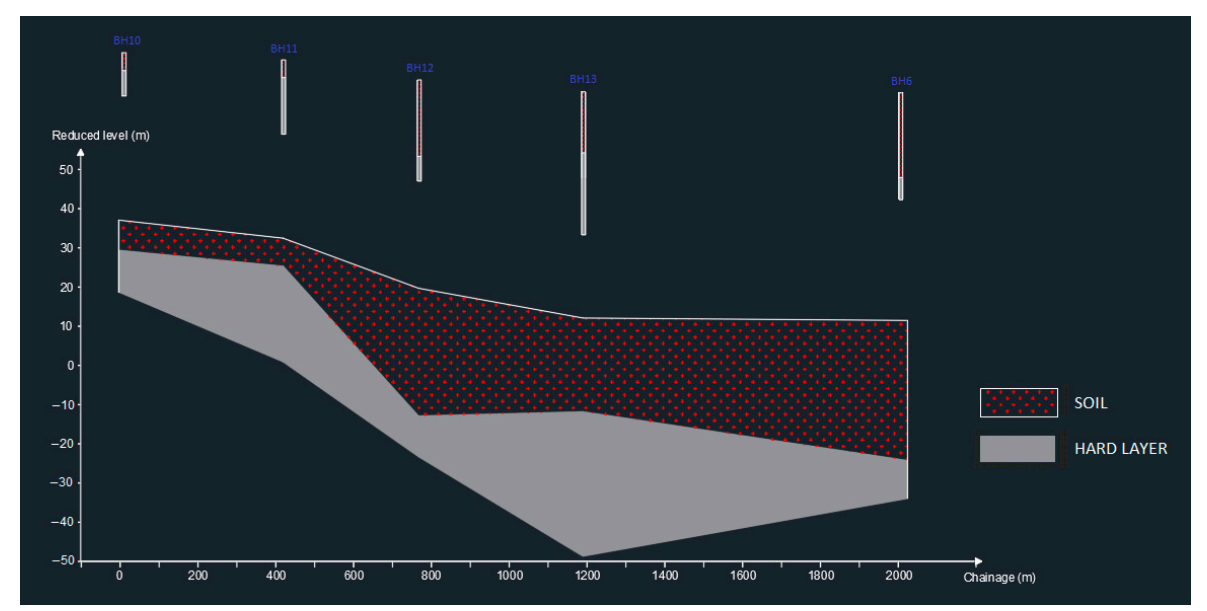

Figure 9. Cross-sectional profile for Case Study 2 based on soil-hard layer/bedrock model. 


\section{Discussion}

The main idea of implementing Building Information Modelling (BIM) is to produce an intelligent model with parametric scripted, as it will generate and interpolate the necessary information from the inputs. The geometric and graphical information is generated with pre-programmed rules or algorithms.

Through the two case studies above, it is apparent that the 3D subsurface models could be used as a useful visualization tool for presenting subsoil conditions at a proposed site. The 3D models provided convenience to engineers for visualizing soil profiles at different detailing levels to accommodate for different needs. The models also facilitated easier storage, accessibility and sharing among stakeholders for future references. For geotechnical analysis and design purposes, engineers can view the profile along any cross section of interest by a few simple clicks. Through the geotechnical BIM, virtual models of subsoil enable project teams to visualize the subsoil profile of the entire proposed development site. This is a revolution to the conventional geotechnical engineering practices whereby the 1D borehole data are interpolated manually to a selected 2D cross-sectional profile for subsequent geotechnical analysis and design. This advancement in technology can minimize the occurrence of human error that relies heavily on individual experience and judgment when interpreting the soil profile, minimize the risk of unforeseen subsoil conditions during the design stage, and provide a better database for future references.

Through Case Study 1, it was learned that managing soil investigation data manually for a large site that was divided into several phases or sub-projects could be highly challenging. By digitizing these data and presenting them in a 3D model, the BIM tool provided a common platform for storing and updating the data whenever new soil investigation data were available. Some procedures of simplifying the soil strata were necessary to minimize the problems of soil pockets bedded into dominant soil layers, particularly for a site with complicated soil strata.

Through Case Study 2, it was learned that manual interpretation of a hard layer for a site with large topographic variations is highly challenging. Typically, sites with large topographic variations tend to have inconsistent hard layers, which may contribute to a huge impact on the selection of foundation type and their associated cost. The implementation of geotechnical BIM enabled visualization of the soil strata and hard layer at any specific location clearly by just a few clicks.

Models of different detailing levels could serve for different applications. Even though a 3D subsurface model with detailed soil descriptions could be highly intricate, this model could be useful for data storage and sharing purposes since all the soil information from the SI report were preserved and modeled. Besides, the model could be useful for detailed analysis and design of underground structures in which any small variation in the composition and stiffness of soil could be considered in the analysis. The presence of small pockets of problematic soil or cavity in the soil profile could be detected easily from the model. A 3D subsurface model with some simplifications of soil strata is useful for presentation or visualization purposes. In geotechnical engineering, it is a common practice that a soil profile is generalized based on the dominant compositions and the range of $\mathrm{SPT}^{\prime} \mathrm{N}$ values to simplify the analysis procedures. This generalization process was normally performed manually, and relied highly upon an individual's judgment and experience. The development of 3D model can facilitate the verification process of the generalized profile, whereby the cross sections along multiple directions can be created within a three-dimensional space. The model that further simplified the soil strata into soil deposits and hard layer/bedrock only could be useful during the preliminary design stage of substructures. For instance, the indicative length of piles can be determined easily from the model if the piles are to be driven to a "set" or hard stratum. Besides, information about the depth of hard stratum is useful for making an appropriate recommendation for the type of foundation to be used for a proposed site.

As evidenced from the present case studies, 3D modelling of subsoils in Malaysia could be challenging, mainly because of the complex soil strata of tropical residual soils. 
The soils could be weathered to different compositions that may contribute to a few tens of soil type combinations. 3D modeling of such intricate soil profile may require significant modeling and computational efforts. Therefore, an adequate generalization effort should be adopted during the data interpretation stage. In the present study, the soil profile generalization procedures were performed manually. This task can be automated by commercial or self-developed software.

Data collection is another challenging task in promoting geotechnical BIM in Malaysia. To extend the implementation of geotechnical BIM to a macro-scale, a centralized soil investigation database system is required. To date, there is still no centralized system for managing the soil investigation data in Malaysia. The existing soil data formats are compartmentalized and non-interchangeable, and thus the process is inadequate for detailed analysis or sharing without extensive pre-processing. One of the major challenges to manage the substructure information is the method to store and preserve the data assets from soil investigation (SI) and land surveying. Both 2D CAD and paper documentation are associated with a limited aspect of information and interoperability. As compared with previous studies on geotechnical BIM which were mainly conducted in developed countries in the European continent [6-10], implementation of the geotechnical BIM process in Malaysia possessed a greater challenge in the data collection phase. This was because most of the soil investigation data in the country are available in the form of hardcopy or softcopy in PDF format. Local industry players do not adhere to a standard format of presenting the soil investigation reports. This required a manual input of soil data into the 3D subsoil model, which can be a significantly tedious and time-consuming task especially when dealing with large amounts of soil data, as evidenced in the present Case Study 1. Even though integration of relevant geotechnical data in an interchangeable format may improve efficiency of design and management process in regards to finance and time factors [10], huge efforts devoted during data collection, data interpretation, and data visualization phases for the geotechnical BIM process should also be accounted for in which a large portion of these tasks still require manual operations. Governance from the relevant authorities is required to ensure that all submissions of soil investigation data are tabulated in a standard format such as that of "AGS format" and are submitted to a centralized database. By doing this, it improves the workflow of geotechnical BIM. All the industry players can work on a universal platform and omit the issues of compatibility when transferring the soil investigation data to different modeling or analysis tools.

\section{Conclusions}

This paper explored the procedures of developing three-dimensional subsurface models through two case studies in Malaysia and identified the associated challenges when performing the modelling. The following conclusions can be drawn from the study:

(i) 3D subsurface models were successfully generated for two case studies in Malaysia using commercial software, AutoCAD Civil 3D 2017 with the extension of Geotechnical Module. The modeling procedures can be divided into three stages, namely data collection, data interpretation, and data visualization.

(ii) 3D subsurface modeling requires significant modeling and computational efforts, particularly when dealing with the tropical residual soil profiles in Malaysia. The soil profiles are highly intricate as the result of intense weathering effects. An adequate soil profile generalization is required during the data interpretation stage.

(iii) Subsurface models with different levels of detailing could serve for different engineering applications, while possessing their own advantages/shortcomings. The model developed based on detailed SI data can be used for detailed analysis and design of substructures. The model developed based on the generalized soil profile is best for presentation purposes. The model developed based on soil and hard strata is useful for preliminary foundation design.

(iv) Data collection is one of the main challenges in promoting geotechnical BIM in Malaysia at a macro-scale. Most of the soil investigation data are available in the 
form of hardcopy or softcopy in PDF format. Local industry players do not adhere to a standard format of presenting the soil investigation reports. There are pressing needs of coordination/governance from the authorities to develop a centralized soil investigation database system for data sharing among geotechnical community in Malaysia.

(v) Geotechnical BIM is still a relatively new concept to the Malaysian construction industry. As evidenced from the present case studies, many of the processes still require manual operations, such as data key-in, soil generalization, data interpretation and verification, etc. Future research may look into automation of these processes to enhance the practicality of implementing geotechnical BIM.

Author Contributions: Conceptualization, M.L.L.; methodology, Y.L.L. and S.L.G.; software, Y.L.L.; validation, S.L.G.; writing—original draft preparation, M.L.L.; writing—review and editing, S.H.L. and S.Y.C.; visualization, S.L.G.; supervision, M.L.L.; project administration, C.H.K.; funding acquisition, M.L.L. and C.H.K. All authors have read and agreed to the published version of the manuscript.

Funding: This research was supported by Ministry of Higher Education (MoHE) of Malaysia through the Fundamental Research Grant Scheme (FRGS), under project number FRGS/1/2018/TK01 /UTAR/02/1. The APC was fully funded by MoHE of Malaysia.

Institutional Review Board Statement: Not applicable.

Informed Consent Statement: Not applicable.

Acknowledgments: This research has been carried out under Fundamental Research Grant Scheme Project FRGS/1/2018/TK01/UTAR/02/1 provided by Ministry of Higher Education (MoHE) of Malaysia.

Conflicts of Interest: The authors declare no conflict of interest.

\section{References}

1. Yusof, M.A.; Mohammad, N.; Mat Derus, Z. Excusable and Compensable Delays in the Construction of Building Project-A Study in the States of Selangor and Wilayah Persekutuan Kuala Lumpur, Malaysia. J. Inst. Eng. Malays. 2007, $68,21-26$.

2. Morin, G. What BIM Can Add to Geotechnical Engineering-BIM+. Available online: https://www.bimplus.co.uk/what-bimcan-add-geotechnical-engineering/ (accessed on 14 August 2021).

3. Taha, M.R.; Hossain, M.K.; Mofiz, S.A. Behaviour and modeling of granite residual soil in direct shear test. J. Inst. Eng. Malays. 2000, 61, 27-40.

4. Townsend, F.C. Geotechnical Characteristics of Residual Soils. J. Geotech. Eng. 1985, 111, 77-94. [CrossRef]

5. Latiffi, A.A.; Mohd, S.; Kasim, N.; Fathi, M.S. Building Information Modeling (BIM) Application in Malaysian Construction Industry. Int. J. Constr. Eng. Manag. 2013, 2, 1-6. [CrossRef]

6. Kessler, H.; Wood, B.; Morin, G.; Gakis, A.; McArdle, G.; Dabson, O.; Fitzgerald, R.; Dearden, R. Building Information Modelling (BIM): A route for geological models to have real world impact. In Proceedings of the Geological Society of America 2015 (GSA 2015); Geological Society of America: Baltimore, MD, USA, 2015; pp. 13-18.

7. Schumann, R. Building Railroads Digitally First. GeoResources 2016, 3, 7-13.

8. Svensson, M.; Ab, T. GeoBIM for optimal use of geotechnical data. In Proceedings of the 17th Nordic Geotechnical Meeting Challenges in Nordic Geotechnic, Reykjavik, Iceland, 25-28 May 2016; pp. 605-612.

9. Morin, G.; Hassall, S.; Chandler, R. Case study-The real life benefits of Geotechnical Building Information Modelling. In Information Technology in Geo-Engineering; Toll, D.G., Ed.; IOS Press: Amsterdam, The Netherlands, 2014; Volume 3, pp. 95-102. [CrossRef]

10. Tawelian, L.R.; Mickovski, S.B. The Implementation of Geotechnical Data into the BIM Process. Procedia Eng. 2016, 143, 734-741. [CrossRef]

11. Tate, R.B.; Tan, D.N.K.; Ng, T.F. Geological Map of Peninsular Malaysia. In Geology of Peninsular Malaysia; Hutchison, C.S., Tan, D.N.K., Eds.; University of Malaya/Geological Society of Malaysia: Kuala Lumpur, Malaysia, 2009.

12. Huat, B.B.K.; David, G.T.; Prasad, A. Handbook of Tropical Residual Soils Engineering, 1st ed.; CRC Press: London, UK, 2012; ISBN 9780415457316.

13. Md Yusoff, Z.; Raju, G.; Nahazanan, H. Static and dynamic behaviour of Kuala Lumpur Limestone. Malays. J. Civ. Eng. 2016, 28, 18-25.

14. Dodd, T.J.H.; Tham Fatt, N.; Qalam A'zad, B.R.; Ramzanee, M.N.; Leslie, A.G.; Dobbs, M.R.; Gillespie, M.R. New insights into the sedimentology of the Kenny Hill Formation, Peninsular Malaysia. In Proceedings of the National Geoscience Conference 2019 (NGC2019); Geological Society of Malaysia: Sabah, Malaysia, 2019; pp. 196-197. 